\title{
How Does Environmental Regulation Affect Industrial Transformation? A Study Based on the Methodology of Policy Simulation
}

\author{
Wei Liu, ${ }^{1}$ Jian Tong, ${ }^{2}$ and Xiaohang Yue ${ }^{3}$ \\ ${ }^{1}$ School of Management Science and Engineering, Dongbei University of Finance and Economics, Dalian 116025, China \\ ${ }^{2}$ School of Economics and Management, Tsinghua University, Beijing 100084, China \\ ${ }^{3}$ Lubar School of Business, University of Wisconsin-Milwaukee, Milwaukee, WI 53211, USA \\ Correspondence should be addressed to Wei Liu; liuweidufe@126.com
}

Received 28 September 2015; Revised 30 January 2016; Accepted 14 February 2016

Academic Editor: Fabio Tramontana

Copyright ( 2016 Wei Liu et al. This is an open access article distributed under the Creative Commons Attribution License, which permits unrestricted use, distribution, and reproduction in any medium, provided the original work is properly cited.

\begin{abstract}
The difference of factor input structure determines different response to environmental regulation. This paper constructs a theoretical model including environmental regulation, factor input structure, and industrial transformation and conducts a policy simulation based on the difference of influencing mechanism of environmental regulation considering industrial heterogeneity. The findings show that the impact of environmental regulation on industrial transformation presents comparison of distortion effect of resource allocation and technology effect. Environmental regulation will promote industrial transformation when technology effect of environmental regulation is stronger than distortion effect of resource allocation. Particularly, command-control environmental regulation has a significant incentive effect and spillover effect of technological innovation on cleaning industries, but these effects do not exist in pollution-intensive industries. Command-control environmental regulation promotes industrial transformation. The result of simulation showed that environmental regulation of market incentives is similar to that of command-control.
\end{abstract}

\section{Introduction}

Environmental regulation is one of the policies and measures by which the government solves "market failure" of environmental issue, which has become an important way to push industrial transformation. The main cause of industrial transformation is technological innovation. According to Porter $[1,2]$, the appropriate environmental regulation policy helps to stimulate the enterprises to carry out technological innovation, which can be called the effect of technological innovation incentive. Jaffe and Palmer [3] present three distinct variants of the so-called Porter Hypothesis, namely, the "weak" version, the "narrow" version, and the "strong" version. Lanoie et al. [4] tested the significance of these different variants of the Porter Hypothesis using data on the four main elements of the hypothesized causality chain (environmental policy, research and development, environmental performance, and commercial performance). They found strong support for the "weak" version and qualified support for the "narrow" version and the "strong" version. Ambec et al. [5] provided an overview of the key theoretical and empirical insights on the Porter Hypothesis to date. Blind [6] differentiated between economic, social, and institutional regulations following the OECD taxonomy on regulations. The results confirmed the hypotheses derived from the conceptual theoretical framework determining technical progress and innovation endogenously and allowing a distinction between short-term and long-term effects. So the influence of environmental regulation on technological innovation is determined by many factors.

In terms of industrial sector, the adjustment of industrial production capacity is related to the proportion of fixed capital in production factors input. The fixed cost is higher relatively in pollution-intensive industries, due to the large fixed capital input, the complexity of technology, and the specificity of equipment. It is difficult to update 
technology for pollution-intensive industries when environmental regulation intensity increases. Pollution-intensive industries may augment production factors input to offset environmental regulation cost, which will cause a distortion effect of resource allocation. In contrast, it is easier to change technology for cleaning industries when environmental regulation intensity increases. Cleaning industries will increase R\&D investment to improve technology to avoid environmental regulation cost, which will cause incentive effects and spillover effects of technological innovation. Therefore, the increase of environmental regulation intensity ultimately drives the adjustment of industrial structure [7].

Many literatures focused on the effect of environmental regulation on industrial structure transformation from proportion of the third industry and secondary industry perspective $[8,9]$. $\mathrm{Li}[8]$ addressed environmental regulations which will improve the proportion of the service sector relative to the industrial sector and promote the adjustment of industrial structure. The previous literatures were more concerned with the incentive effect of environmental regulation on technological innovation within the industrial sector. For instance, Bai and Song [10] found that environmental regulation can improve the efficiency of Chinese thermal power as a whole and cause incentive effects of technological innovation. Zhang et al. [11] conducted an empirical test on industrial sectors of 30 provinces in China and found that the effect of environmental regulation on technological progress rate is different among different regions. In recent years, many researchers found that industrial heterogeneity plays a very important role in the relationship between environmental regulation and technological innovation, but the conclusion is not consistent [12-15]. Li and Tao [12] indicated environmental regulation intensity of heavy pollution industry can promote the industrial green total factor productivity, the environmental regulation intensity of the moderate pollution industry is weak, and technological innovation can be early breakthrough " $U$ " inflection point for light pollution industry. Nie and Huang [15] found the current strength of environmental regulation hinders the improvement of moderate energy-intensive industries in total factor energy productivity, technological innovation, and efficiency improvements; highly energy-intensive industries' environmental regulatory intensity does not significantly influence the total factor energy productivity; for the mild energy-intensive industries, the intensity of environmental regulation promotes technological innovation.

The existing literatures mostly focused on the effect of environmental regulation on industrial structure at the country or region level and paid little attention to the impact of environmental regulation on industrial transformation inside the industrial sector. In the meantime, the structure of factors input may cause different response to environmental regulation in pollution-intensive industries and cleaning industries. Therefore, we construct a theoretical model to analyze different effect of environmental regulation on heterogeneity industries in this paper. Then we conduct a simulation to examine the effect of different environmental regulation policy and put forward some suggestion.

\section{The Mathematical Model}

Environmental regulation includes command-control and market incentive regulation. In this paper, we select environmental regulation intensity as a proxy of command-control environmental regulation, environment tax, and environmental technology subsidies as a proxy of market incentive environmental regulation. Further we assume that technology is relatively fixed for pollution-intensive industries, but environmental technology will continue to change for cleaning industries in the process of production. Pollutionintensive industries are likely to increase inputs to offset the cost of regulation when environmental regulation intensity increases, namely, the distortion effect of resource allocation. And cleaning industries will promote the environmental technology, namely, the incentive effect of technological innovation. At the same time, the technology change will make organization structure and management mode change further, eventually leading to improvements in total factor productivity, namely, technology spillover effect. In short, the distortion effect of resources allocation represents the distortion of environmental regulation; moreover incentive effect and spillover effect of technological innovation reflect the externality of environment regulation. When distortion effect of environmental regulation is bigger than the externality (namely, the benefit that pollution-intensive industries accept tax punishment and increase factors input is higher), environmental regulation will inhibit industrial transformation. When the externality of environmental regulation is greater than distortion effect (namely, incentive effect and spillover effect of technology innovation for cleaning industry is higher), environmental regulation will promote industrial transformation. In the following section, the dynamic general equilibrium model is selected to analyze the mechanism.

2.1. The Effect of Environmental Regulation on PollutionIntensive Industries. The capital, labor, and environmental resources are input in the process of production in pollutionintensive industry. Because of consumption of environmental resources, pollution emissions will be produced. Here, environmental resources include fossil energy and other natural resources, for instance, soil and water and air. As mentioned above, pollution-intensive industries are restricted by replacement cost of machinery and equipment, so environmental technology is relatively fixed, which can only accept tax penalties. Therefore, the production function in pollution-intensive industries is as follows:

$$
Y_{1 t}=\Phi_{0} A_{1 t} K_{1 t}^{\alpha_{1}} L_{1 t}^{\beta_{1}} E_{1 t}^{\gamma_{1}},
$$

where $\Phi_{0}$ denotes fixed environmental technology in pollution-intensive industries. $A_{1 t}$ represents total factor productivity. $K_{1 t}, L_{1 t}$, and $E_{1 t}$ denote capital, labor, and environmental resource, respectively.

The function of pollution emission in pollution-intensive industries is as follows:

$$
E M_{1 t}=\Psi\left(\Phi_{0}, E_{1, t}\right)=\frac{\rho_{1} E_{1, t}^{\rho_{2}}}{\Phi_{0}},
$$


where $\Psi_{\Phi}^{\prime}\left(\Phi_{t}, E_{1, t}\right)<0$ denotes that environmental technology level is higher and environmental pollution emissions are lower. $\Psi_{E}^{\prime}\left(\Phi_{t}, E_{t}\right)>0$ denotes that the more environmental resource is consumed, the more environmental pollution emissions are produced.

The government will levy a tax on pollution-intensive industry. When environmental regulation intensity is high, enterprises require burdening higher cost of tax. Therefore, there is a trade-off between increasing environmental resources consumption and reducing the environment resources consumption. So the profit function in pollutionintensive industries is as follows:

$$
\Pi_{1 t}=P_{1 t} Y_{1 t}-r_{1 t} K_{1 t}-w_{t} L_{1 t}-P_{t}^{e} E_{1 t}-\tau(\phi) E M_{1 t},
$$

where $\tau(\phi)=\tau+\kappa_{0} \phi^{\kappa_{1}}$ represents the tax rate of environmental pollution which is related to environmental regulation intensity. Enterprises required undertaking the higher cost of tax, when environmental regulation intensity is high.

By solving the profit maximization problem, we can obtain the first-order conditions:

$$
\begin{array}{r}
\alpha_{1} P_{1 t} \Phi_{0} A_{1 t} K_{1 t}^{\alpha_{1}-1} L_{1 t}^{\beta_{1}} E_{1 t}^{\gamma_{1}}=r_{1 t} \\
\beta_{1} P_{1 t} A_{1 t} K_{1 t}^{\alpha_{1}} L_{1 t}^{\beta_{1}-1} E_{1 t}^{\gamma_{1}}=\omega_{t} \\
\gamma_{1} P_{1 t} \Phi_{0} A_{1 t} K_{1 t}^{\alpha_{1}} L_{1 t}^{\beta_{1}} E_{1 t}^{\gamma_{1}-1}-P_{t}^{e}-\tau(\phi) \frac{\rho_{1} \rho_{2} E_{1, t}^{\rho_{2}-1}}{\Phi_{0}}=0 .
\end{array}
$$

Equations (4) and (5) denote the price of capital and labor equal to their marginal output, respectively. Equation (6) denotes the marginal output of environmental resources is equal to the sum of environmental resources price and tax cost which is caused by increasing environmental resources consumption to produce environmental pollution increment.

\subsection{The Effect of Environmental Regulation on Cleaning Indus-} tries. Cleaning industries generally include large enterprises with the stronger comprehensive technology research and development ability and small businesses with emerging technology. The higher the intensity of environmental regulation, the stronger the motivation of green technology strategy carried out by cleaning industries. According to Porter $[1,2]$, the appropriate environmental regulation policy helps to stimulate the enterprises to carry out technological innovation, which can be called the effect of technological innovation incentive. The cleaning industries will increase green R\&D investment, improve the level of human capital, and develop perfect system environment, which in turn improve technological management level and change organization structure and management mode, eventually leading to improvements in total factor productivity, namely, technology spillover effect. Cleaning industries also will discharge pollution in the process of production. In order to expand technology innovation incentive effect, the government will impose subsidy to R\&D investment of environmental technology in cleaning industries. Therefore, the production function in cleaning industries is as follows:

$$
\begin{aligned}
Y_{2 t} & =\Phi\left(\phi_{t}, K_{r d, t}\right) A_{2 t} K_{2 t}^{\alpha_{2}} L_{2 t}^{\beta_{2}} E_{2 t}^{\gamma_{2}} \\
\Phi\left(\phi_{t}, K_{r d, t}\right) & =\phi_{t} \rho_{3} K_{r d, t}^{\rho_{4}}+\Phi_{1},
\end{aligned}
$$

where $\phi$ is environmental regulation intensity. $\Phi_{t}$ is initial level of environmental technology in cleaning industries. $\Phi_{\phi}^{\prime}\left(\phi, K_{r d, t}\right)>0$ and $\Phi_{K}^{\prime}\left(d, K_{r d, t}\right)>0$ denote that the higher environmental regulation intensity and the more R\&D investment of green technologies, the greater spillover effect of green technology and production technology, respectively. $A_{2 t}$ denotes total factor productivity in cleaning industries. $K_{2 t}, L_{2 t}$, and $E_{2 t}$ represent capital, labor, and environmental resource, respectively.

Different from pollution-intensive industries, cleaning industries not only can improve the level of environmental technology to control pollution emissions, but can reduce production to control pollution emissions. So the function of pollution emission in cleaning industries is as follows:

$$
E M_{2 t}=\Psi\left(\Phi_{t}, E_{2, t}\right)=\frac{\rho_{5} E_{2, t}^{\rho_{6}}}{\Phi_{t}},
$$

where $\Psi_{\Phi}^{\prime}\left(\Phi_{t}, E_{2, t}\right)<0$ denotes that environmental technology level is higher and environmental pollution emissions are lower. $\Psi_{E}^{\prime}\left(\Phi_{t}, E_{t}\right)>0$ denotes that the more environmental resource is consumed, the more environmental pollution emissions are produced.

The profit function in cleaning industries is as follows:

$$
\begin{aligned}
\Pi_{2 t}= & P_{2 t} Y_{2 t}-r_{2 t} K_{2 t}-w_{t} L_{2 t}-P_{t}^{e} E_{2 t}-\tau(\phi) E M_{2 t} \\
& -\left(r_{r d, t}-v_{0}\right) K_{r d, t},
\end{aligned}
$$

where $v_{0}$ denotes the subsidy that government imposes to R\&D investment of environmental technology.

By solving the profit maximization problem, we can obtain the first-order conditions:

$$
\begin{aligned}
& \alpha_{2} P_{2 t} \Phi\left(\phi_{t}, K_{r d, t}\right) A_{2 t} K_{2 t}^{\alpha_{2}-1} L_{2 t}^{\beta_{2}} E_{2 t}^{\gamma_{2}}=r_{2 t} \\
& \beta_{2} P_{2 t} \Phi\left(\phi_{t}, K_{r d, t}\right) A_{2 t} K_{2 t}^{\alpha_{2}} L_{2 t}^{\beta_{2}-1} E_{2 t}^{\gamma_{2}}=\omega_{t} \\
& \gamma_{2} P_{2 t} \Phi\left(\phi_{t}, K_{r d, t}\right) A_{2 t} K_{2 t}^{\alpha_{2}} L_{2 t}^{\beta_{2}-1} E_{2 t}^{\gamma_{2}-1}-P_{t}^{e} \\
& \quad-\tau(\phi) \frac{\rho_{5} \rho_{6} E_{2, t}^{\rho_{6}-1}}{\Phi_{t}}=0 \\
& P_{2 t} \phi_{t} \rho_{3} \rho_{4} K_{r d, t}^{\rho_{4}-1} A_{2 t} K_{2 t}^{\alpha_{2}} L_{2 t}^{\beta_{2}} E_{2 t}^{\gamma_{2}} \\
& \quad+\tau(\phi) \frac{\rho_{5} E_{2, t}^{\rho_{6}}}{\Phi_{t}^{2}} \phi_{t} \rho_{3} \rho_{4} K_{r d, t}^{\rho_{4}-1}-\left(r_{r d, t}-v_{0}\right)=0 .
\end{aligned}
$$

Equations (10) and (11) denote the price of capital and labor equals their marginal output. Equation (12) denotes that the marginal output of environmental resources is equal to the 
sum of environmental resources price and tax cost which is caused by increasing environmental resources consumption to produce environmental pollution increment. Equation (13) denotes that the price of $\mathrm{R} \& \mathrm{D}$ capital of environmental technology is equal to the sum of marginal output increment and the reduction of tax cost caused by environmental technology innovation and the governmental subsidy for $\mathrm{R} \& \mathrm{D}$ investment of environmental technology.

2.3. The Production of Environmental Industries. Environment and resources also need to be produced by capital and labor, such as the extraction of fossil resource, water resource supply, and coal mining. Production function of environmental industries is as follows:

$$
E_{t}=A_{3 t} K_{3 t}^{\alpha_{3}} L_{3 t}^{1-\alpha_{3}} .
$$

The profit function of environmental industries is as follows:

$$
\Pi_{3 t}=P_{t}^{e} E_{t}-r_{3 t} K_{3 t}-w_{t} L_{3 t}
$$

By solving the profit maximization problem, we can obtain the first-order conditions:

$$
\begin{aligned}
\alpha_{3} P_{t}^{e} A_{3 t} K_{3 t}^{\alpha_{3}-1} L_{3 t}^{1-\alpha_{3}} & =r_{3 t} \\
\left(1-\alpha_{3}\right) P_{t}^{e} A_{3 t} K_{3 t}^{\alpha_{3}} L_{3 t}^{-\alpha_{3}} & =\omega_{t} .
\end{aligned}
$$

Equation (16) denotes that the price of capital and labor equals their marginal output in environmental industries.

2.4. The Consumption of the Public. The public achieves a lifetime utility maximization by choosing between clean product and the polluting products and between consumption and saving. Objective function of the public is as follows:

$$
\max \sum_{t=0}^{\infty}\left(\frac{C_{1 t}^{1-\sigma_{1}}}{1-\sigma_{1}}+\zeta \frac{C_{2 t}^{1-\sigma_{2}}}{1-\sigma_{2}}\right)
$$

where $\sigma_{1}$ and $\sigma_{2}$ denote the intertemporal substitution elasticity of two kinds of products, respectively. $\zeta$ depicts how the public pay close attention to the two kinds of products. The budget constraint equations of the public are as follows:

$$
\begin{aligned}
& P_{1 t} C_{1 t}+P_{2 t} C_{2 t}+Q_{t} S_{t}+\Pi_{t} G_{t} \\
& \quad \leq r_{1 t} K_{1 t}+r_{2 t} K_{2 t}+r_{r d, t} K_{r d, t}+r_{3 t} K_{3 t}+w_{t} L_{t} \\
& S_{t}=S_{1 t}^{\theta_{1}} S_{2 t}^{1-\theta_{1}} \\
& Q_{t}=\left(\frac{P_{1 t}}{\theta_{1}}\right)^{\theta_{1}}\left(\frac{P_{2 t}}{1-\theta_{1}}\right)^{1-\theta_{1}} \\
& G_{t}=G_{1 t}^{\theta_{2}} G_{2 t}^{1-\theta_{2}} \\
& \Pi_{t}=\left(\frac{P_{1 t}}{\theta_{2}}\right)^{\theta_{2}}\left(\frac{P_{2 t}}{1-\theta_{2}}\right)^{1-\theta_{2}},
\end{aligned}
$$

where $S_{1 t}$ and $S_{2 t}$ denote savings of the public for the two kinds of products, respectively. $S_{t}$ is the sum of $S_{1 t}$ and $S_{2 t}$. $\theta_{1}$ is substitution elasticity of the two kinds of savings. $Q_{t}$ is the price of $S_{t}$. $G_{1 t}$ and $G_{2 t}$ denote the government purchase of the two kinds of products, respectively. $G_{t}$ is the sum of $G_{1 t}$ and $G_{2 t} . \theta_{2}$ is substitution elasticity of the two kinds of products which the government purchases. $\Pi_{t}$ is the price of $G_{t}$.

By solving the utility maximization problem of the public, we can obtain the first-order conditions:

$$
\begin{aligned}
C_{1 t}^{-\sigma_{1}} & =\lambda_{t} P_{1 t} \\
\zeta C_{2 t}^{-\sigma_{2}} & =\lambda_{t} P_{2 t} \\
\beta \lambda_{t+1} r_{1 t+1}-\lambda_{t} Q_{t}+\beta \lambda_{t+1} Q_{t+1}\left(1-\delta_{1}\right) & =0 \\
\beta \lambda_{t+1} r_{2 t+1}-\lambda_{t} Q_{t}+\beta \lambda_{t+1} Q_{t+1}\left(1-\delta_{2}\right) & =0 \\
\beta \lambda_{t+1} r_{r d, t+1}-\lambda_{t} Q_{t}+\beta \lambda_{t+1} Q_{t+1}\left(1-\delta_{r d}\right) & =0 \\
\beta \lambda_{t+1} r_{3 t+1}-\lambda_{t} Q_{t}+\beta \lambda_{t+1} Q_{t+1}\left(1-\delta_{3}\right) & =0 .
\end{aligned}
$$

Equations (19) and (20) denote that the marginal utility of consumption of pollution product and clean product is equal to the marginal income of investment, respectively, namely, intertemporal substitution equation. Equations (21)-(24) are Euler equations.

In particular, the equation of industry transformation is as follows:

$$
\operatorname{STR}=\frac{Y_{2}}{Y_{1}} .
$$

2.5. Model Solutions. The first-order conditions combined with capital formation equation, the government budget constraint equation, and market clearing condition constitute our theoretical model. We can solve the theoretical model. The optimization problem that theoretical model solves is to configure the limited resource among $K_{1 t}, L_{1 t}, E_{1 t}, K_{2 t}$, $L_{2 t}, E_{2 t}, K_{3 t}$, and $L_{3 t}$, so as to maximize profits and the lifetime utility of the typical families. By solving theoretical model, we cannot get analytical solutions of $P_{2}, P_{e}, \omega, K_{r d}$, $E_{1}$, and $E_{2}$, because there is a complex nonlinear relationship among them. Equations (26) are steady state equations of the equilibrium solution. Industrial structure is the optimal structure under the steady state of model, because it achieves profits maximization and lifetime utility maximization of representative families simultaneously, which is to maximize the social welfare. The optimal industrial structure is determined by the parameters of the model at the same time based on the steady state equations (26); namely, the optimal industrial structure is a function of environmental regulation policy. Industrial structure transition is decided by the government's environmental regulation policy. Pollution-intensive industries will gradually reduce the scale of production to drop cost, and cleaning industries will improve the environmental technology which is affected by technology innovation incentive effect when the government makes a tougher environmental regulation policy. Technology spillover effect leads to the improvement of total factor productivity which will promote the cleaning production scale to achieve the aim 
TABLE 1: The division of cleaning industries and pollution-intensive industries.

\begin{tabular}{|c|c|c|c|}
\hline \multicolumn{3}{|c|}{ Cleaning industries } & \multirow{2}{*}{$\frac{\text { Pollution-intensive industries }}{\text { Manufacture of foods }}$} \\
\hline 1 & Manufacture of electrical machinery and equipment & 1 & \\
\hline 2 & Manufacture of articles for culture, education, and sport activity & 2 & Processing of food from agricultural products \\
\hline 3 & Printing and reproduction of recording media & 3 & Manufacture of textile \\
\hline 4 & $\begin{array}{c}\text { Manufacture of communication equipment, computer, and } \\
\text { other electronic equipment }\end{array}$ & 4 & Production and distribution of gas \\
\hline 5 & Manufacture of furniture & 5 & Manufacture of beverage \\
\hline 6 & Manufacture of textile wearing apparel, Footwear, and caps & 6 & Extraction of petroleum and natural gas \\
\hline 7 & Manufacture of general purpose machinery & 7 & Production and distribution of water \\
\hline 8 & Manufacture of tobacco & 8 & Manufacture and processing of nonferrous metals \\
\hline 9 & Manufacture of transport equipment & 9 & Manufacture of chemical raw material and chemical products \\
\hline 10 & $\begin{array}{c}\text { Manufacture of measuring instrument, machinery for cultural } \\
\text { and office work }\end{array}$ & 10 & Manufacture of chemical fiber \\
\hline 11 & Manufacture of special purpose machinery & 11 & Manufacture of nonmetallic mineral products \\
\hline 12 & Manufacture of metal products & 12 & Manufacture and processing of ferrous metals \\
\hline 13 & Manufacture of leather, fur, feather, and their products & 13 & Mining and washing of coal \\
\hline 14 & Extraction of petroleum and natural gas & 14 & Mining and processing of nonmetal ores \\
\hline 15 & $\begin{array}{c}\text { Processing of timbers and manufacture of wood, bamboo, } \\
\text { rattan, palm, and straw }\end{array}$ & 15 & Manufacture of paper and paper products \\
\hline 16 & Manufacture of rubber and plastic & 16 & Production and supply of electric power and heat power \\
\hline \multirow[t]{2}{*}{17} & Manufacture of medicines & 17 & Mining of ferrous metal ores \\
\hline & & 18 & Mining of nonferrous metal ores \\
\hline
\end{tabular}

Source of date: China Industry Economy Statistical Yearbook.

of industrial transformation. There are more than a dozen exogenous parameters in steady state equations, which have complex nonlinear relationship. Therefore, we analyze the existence of the technological innovation incentive effect and the technology spillover effect and the mechanism of environmental regulation on industrial transformation by simulation computation method with MATLAB software:

$$
\begin{aligned}
Y_{1}= & \Phi_{0} A_{1} K_{1}^{\alpha_{1}} L_{1}^{\beta_{1}} E_{1}^{\gamma_{1}} \\
\frac{Y_{2} P_{2} \phi \rho_{3} \rho_{4} K_{r d}^{\rho_{4}-1}}{\phi \rho_{3} K_{r d}^{\rho_{4}}+1}= & -\tau(\phi) \frac{\rho_{5} E_{2}^{\rho_{6}}}{\left(\phi \rho_{3} K_{r d}^{\rho_{4}}+1\right)^{2}} \phi \rho_{3} \rho_{4} K_{r d}^{\rho_{4}-1} \\
& +r_{r d}-\nu_{0} \\
Y_{2}= & \left(\phi \rho_{3} K_{r d}^{\rho_{4}}+1\right) A_{2} K_{2}^{\alpha_{2}} L_{2}^{\beta_{2}} E_{2}^{\gamma_{2}} \\
C_{2}^{-\sigma_{2}}= & \frac{C_{1}^{-\sigma_{1}}}{P_{1}} P_{2} \\
E= & A_{3} K_{3}^{\alpha_{3}} L_{3}^{1-\alpha_{3}} \\
L_{1}+L_{2}+L_{3}= & 1 .
\end{aligned}
$$

\subsection{Calibration of Parameters}

(1) The Division of Cleaning Industries and Pollution-Intensive Industries. The division standard of industrial sectors is in accordance with "China Industry Economy Statistical Yearbook." To be sure, because the data is missing partly in Manufacture of Artwork and Other Manufacture, recycling and processing of waste resource and old materials, and Mining of Other Ores, we remove these subindustries. In addition, we incorporate manufacture of plastic and manufacture of rubber to maintain consistent statistical standard, due to industrial classification standard changed in different years. After the adjustment, we get 35 subindustries. Further, all the industries are divided into cleaning industries and pollution-intensive industries based on the median of the pollution emission intensity. The calculation of the pollution emission intensity (EMI) is as follows.

(1) To calculate pollutant emissions per unit of output in each sector, namely, $U E_{i j}=E_{i j} / Y_{i}$, where $E_{i j}$ is pollutant emission $j$ of sector $i, Y_{i}$ is gross value of industrial output in each sector.

(2) To standardize pollutant emissions per unit of output in each industry,

$$
U E_{i j}^{\prime}=\frac{U E_{i j}-\min \left(U E_{j}\right)}{\max \left(U E_{j}\right)-\min \left(U E_{j}\right)},
$$

where $U E_{i j}$ denotes pollutant emissions per unit of output in each sector. $\max \left(U E_{j}\right)$ and $\min \left(U E_{j}\right)$ denote the maximum and minimum of pollutant emission $j$ across all industries, respectively. $U E_{i j}^{\prime}$ is standardized value of pollutant emission per unit of output in each industry.

(3) To calculate weighted average of standardized value of pollutant emission, we can obtain industry pollution emission intensity. The division of cleaning industries and pollution-intensive industries is shown in Table 1. 
TABLE 2: The estimated results of the production function and technological progress rate.

(1)

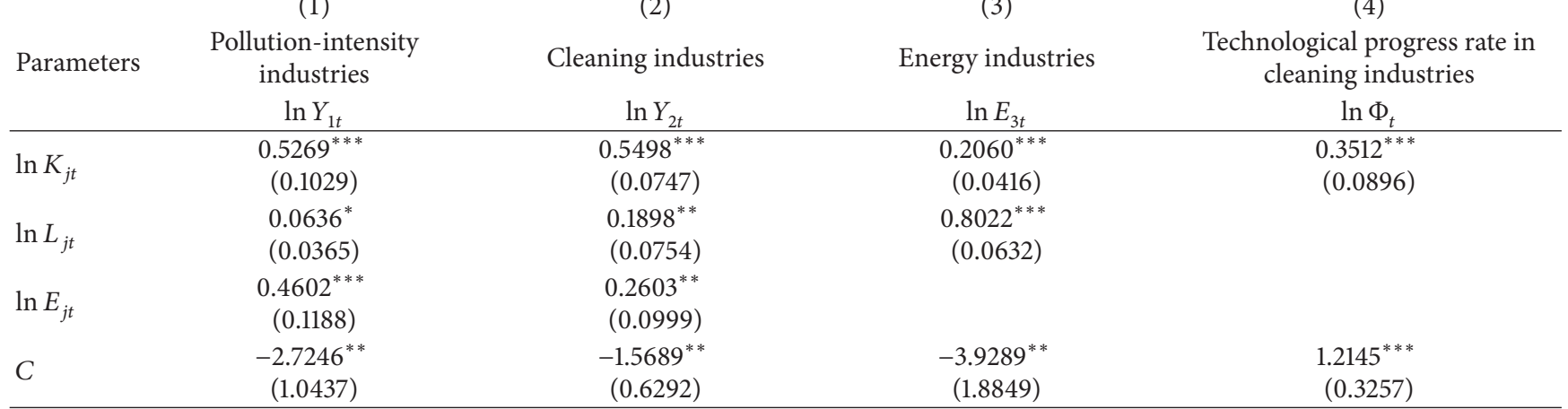

Note: standard errors in parentheses. ${ }^{* * *} p<0.01 ;{ }^{* *} p<0.05 ;{ }^{*} p<0.1$.

(2) Environmental Regulation Intensity. Environmental regulation is measured from 6 dimensions in the previous literature [11]. First is the type of environmental regulation policy. Second is the proportion of investment of pollution treatment in total cost or output value. Third is running cost of pollution control facilities. Fourth is the per capita income. Fifth is the number of governments' inspection. Sixth is the volume of pollution emissions. Considering the availability of industry data, we select running cost of pollution control facilities as the measurement of environmental regulation intensity. According to Shen [13], we choose the proportion of running cost of pollution control that accounts for industrial output as a proxy. The total running cost of pollution control is the sum of running cost of wastewater and waste gas control in each sector. The data source of environmental variables is "China Environment Statistical Yearbook" and the data source of industrial output is "China Industrial Economic Statistical Yearbook.”

(3) The Estimation of Production Function in PollutionIntensity Industries and Cleaning Industries. We estimate the production functions of cleaning industries, pollutionintensity industries, and energy industries (here, we use mining and washing of coal to substitute energy industries) based on panel data in 30 provinces (excluding Tibet) from 2002 to 2012. And we decompose total factor productivity to get technological progress rate and do regression analysis between technological progress rate and $\mathrm{R} \& \mathrm{D}$ investment in cleaning industries.

The regression results are shown in Table 2.

(4) The Estimation of the Function of Pollution Emissions. Since the data of waste water and solid waste are missing partly, we select the volume of $\mathrm{SO}_{2}$ emissions as a proxy in pollution-intensity industries and cleaning industries. We construct the regression equation in which energy consumption is independent variable and the volume of pollution emissions is dependent variable.

The results are shown in Table 3.

(5) The Other Parameters in the Model. Because it is difficult to collect the data of government green purchase and consumption, we set up the other parameters based on Dong et al. [16],

TABLE 3: The estimated results of the function of pollution emissions.

(1)

\begin{tabular}{lcc} 
Parameters & $\begin{array}{c}\text { Pollution-intensity } \\
\text { industries }\end{array}$ & Cleaning industries \\
& $\ln E M_{1 t}$ & $\ln E M_{2 t}$ \\
\hline $\ln \Phi_{j t}$ & -0.0102 & $-0.0156^{*}$ \\
& $(0.1160)$ & $(0.0087)$ \\
$\ln E_{j t}$ & $0.7188^{* * *}$ & $0.6902^{* * *}$ \\
& $(0.0407)$ & $(0.0421)$ \\
$C$ & $6.5605^{* * *}$ & $6.7641^{* * *}$ \\
& $(0.3397)$ & $(0.3461)$ \\
\hline
\end{tabular}

Note: standard errors in parentheses. ${ }^{* * *} p<0.01 ;{ }^{*} p<0.1$.

Acemoglu et al. [17], and Huang and Lin [18]. The settings of parameters are as follows: $\beta=0.99, \theta_{1}=6.8, \theta_{2}=0.015$, $\delta_{1}=0.2, \delta_{2}=0.15, \delta_{r d}=0.2, \delta_{3}=0.2, \sigma_{1}=5$, and $\sigma_{2}=4$.

\section{The Policy Simulation}

\subsection{The Impact of Command-Control Environmental Regula- tion on the Industrial Transformation}

(1) Incentive Effects of Technological Innovation. Figure 1 is a comparison of the existence situation related to technological innovation incentive effects of the environmental regulation intensity in different types of the industry. As shown in Figure 1, the enhancement of the environmental regulation intensity does not affect the level of environmental technology as for pollution-intensive industries but promotes the cleaning industries to enhance their level of the environmental technology. It means that technological innovation incentive effects of the environmental regulation intensity do not exist in terms of pollution-intensive industries, while they exist in the cleansing industries. The cause of this phenomenon is the difference of the cost input model between these two types of industry.

(2) Technology Spillover Effect. Figure 2 is a comparison of the existence situation related to technology spillover effects of the environmental regulation intensity in different types 

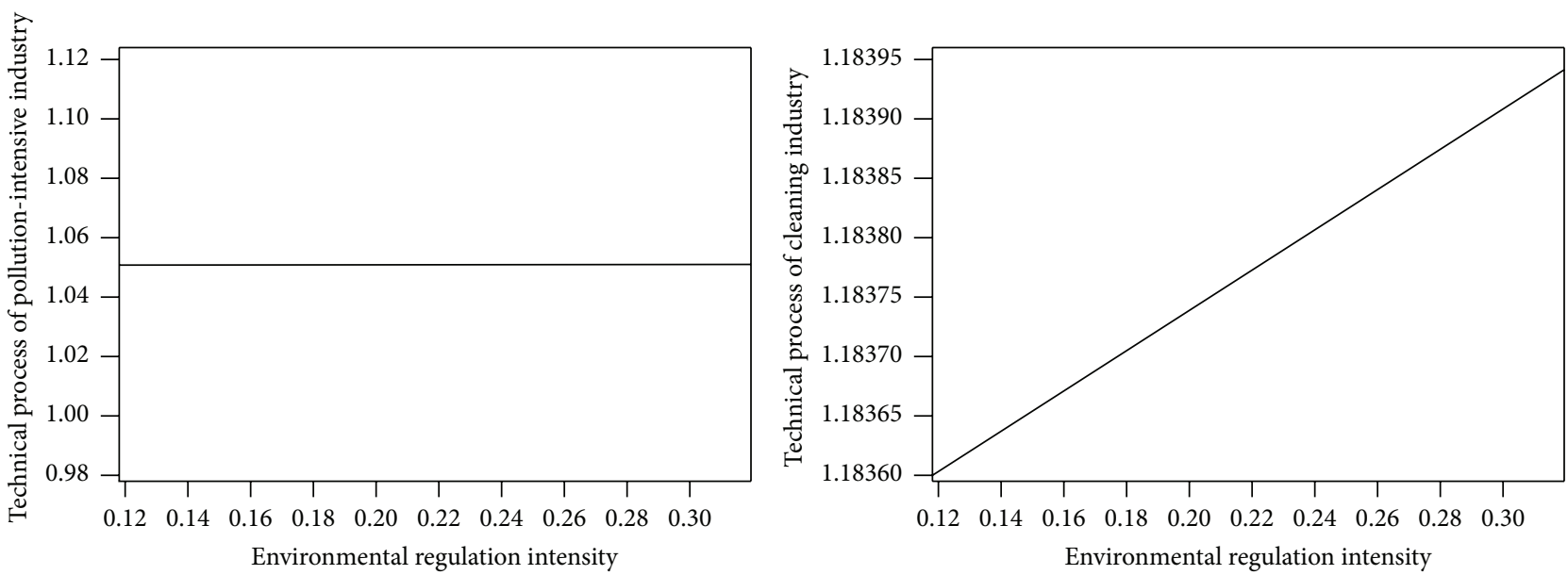

FIGURE 1: The existence analysis of technological innovation incentive effects of command-control environmental regulation.
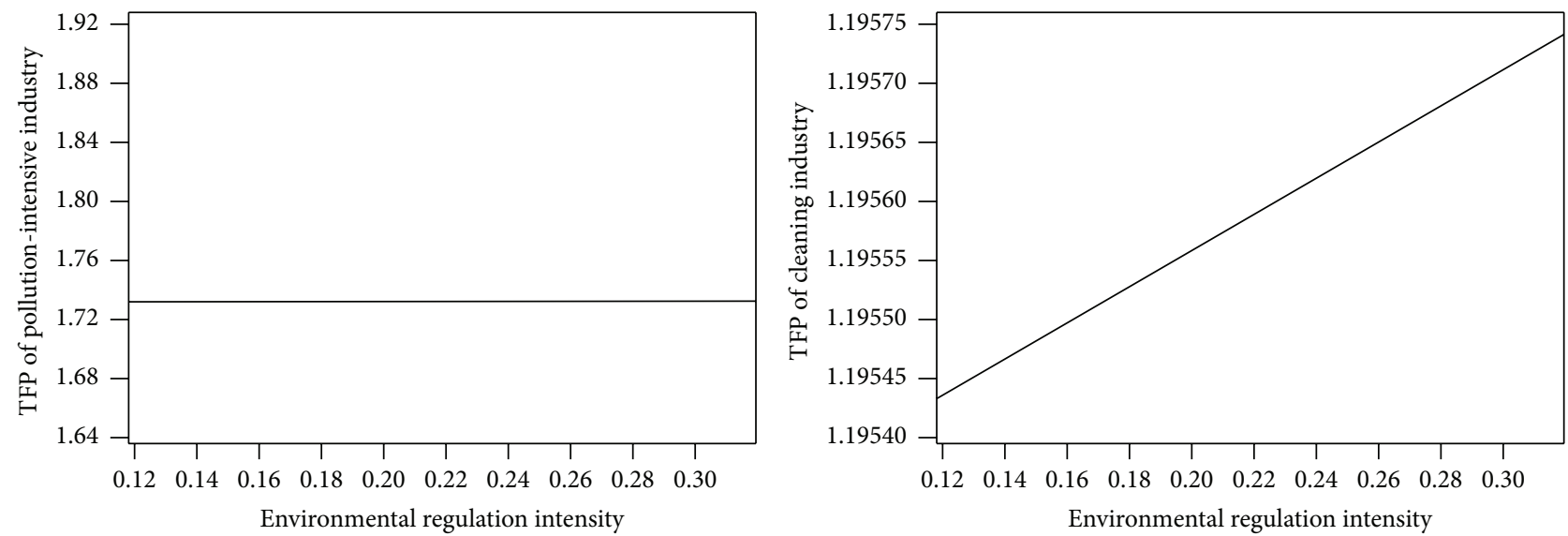

FIGURE 2: The existence analysis of technology spillover effects of command-control environmental regulation.

of the industry. As shown in Figure 2, the enhancement of the environmental regulation intensity does not affect the total factor productivity as for pollution-intensive industries but leads to the increase of the total factor productivity in cleaning industries. It means that technology spillover effects of the environmental regulation intensity do not exist in the pollution-intensive industries, while they exist in the cleansing industries.

(3) The Impact of Command-Control Environmental Regulation on the Industrial Transformation. Figure 3 is the impact of the command-control environmental regulation on the industrial transformation. As shown in Figure 3, when the environmental regulation intensity is enhanced, those enterprises will afford heavier tax if they increase pollution emissions. Since the environmental technology of contaminative enterprises is relatively fixed without any other responses except reducing the yield, the pollutionintensive industries still carry out the original mode of production but the equilibrium will be moved down along the original production function. However, the cleansing industries have the subjective initiative in the process of tax

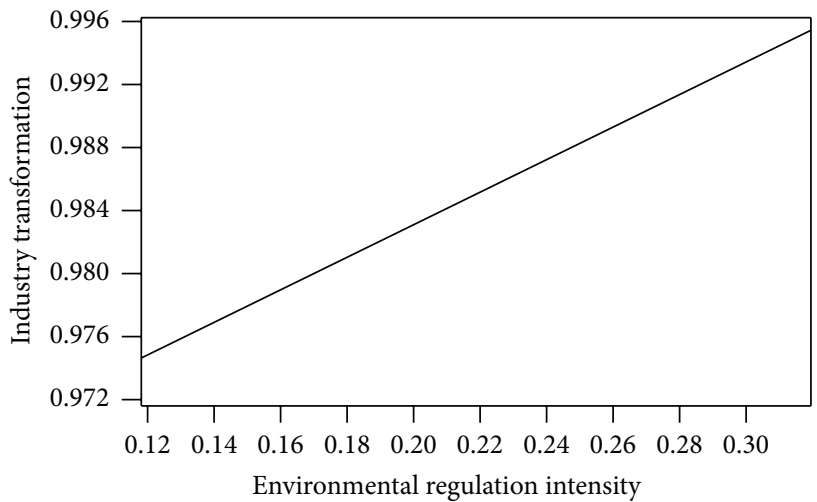

FIGURE 3: The impact of command-control environmental regulation on the industrial transformation.

cost raise. Reduction of yield cannot bring the marketing competitive edge for cleansing industries under the condition of environmental tax. Thus, the cleansing industries need to increase the research input of environmental technology to 

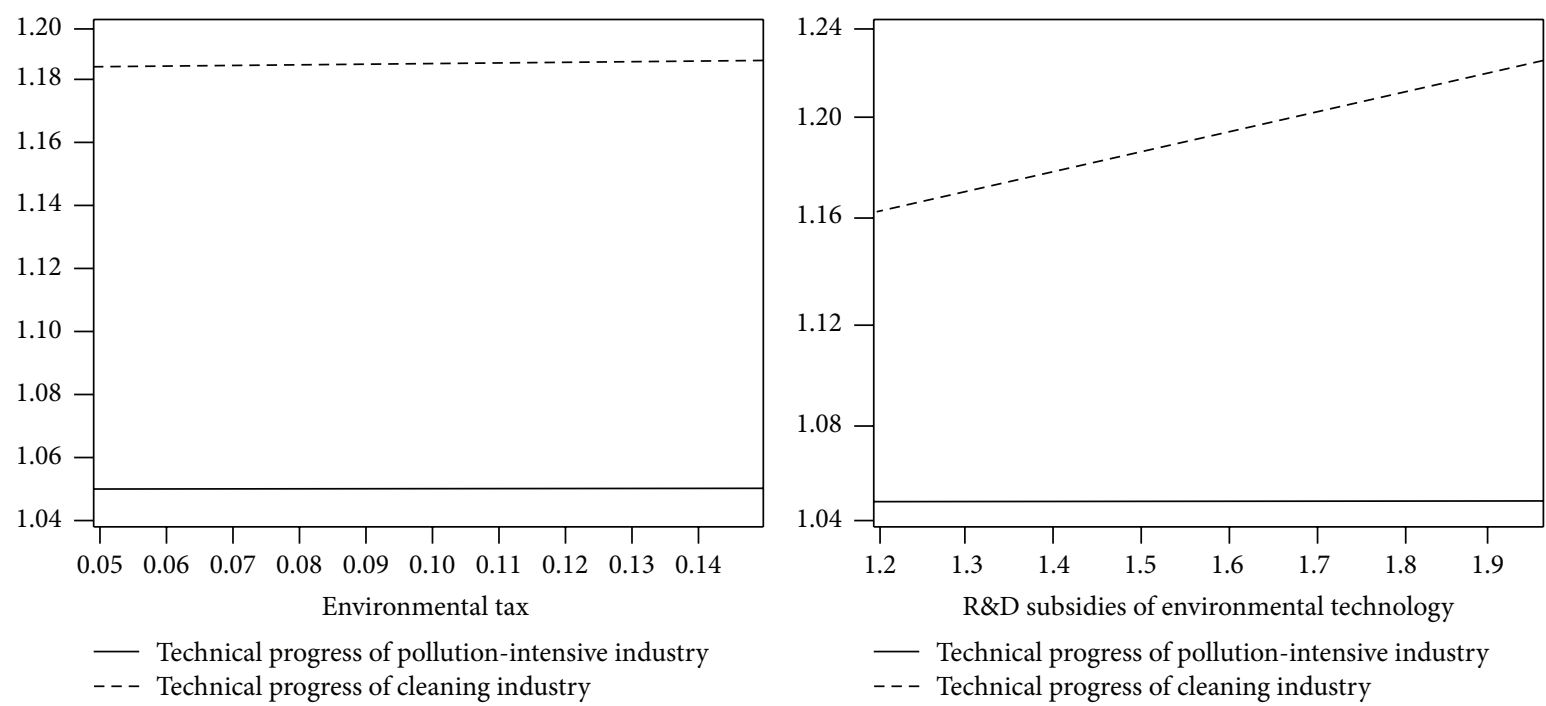

FIgURE 4: The existence analysis of technological innovation incentive effects of market incentives environmental regulation.
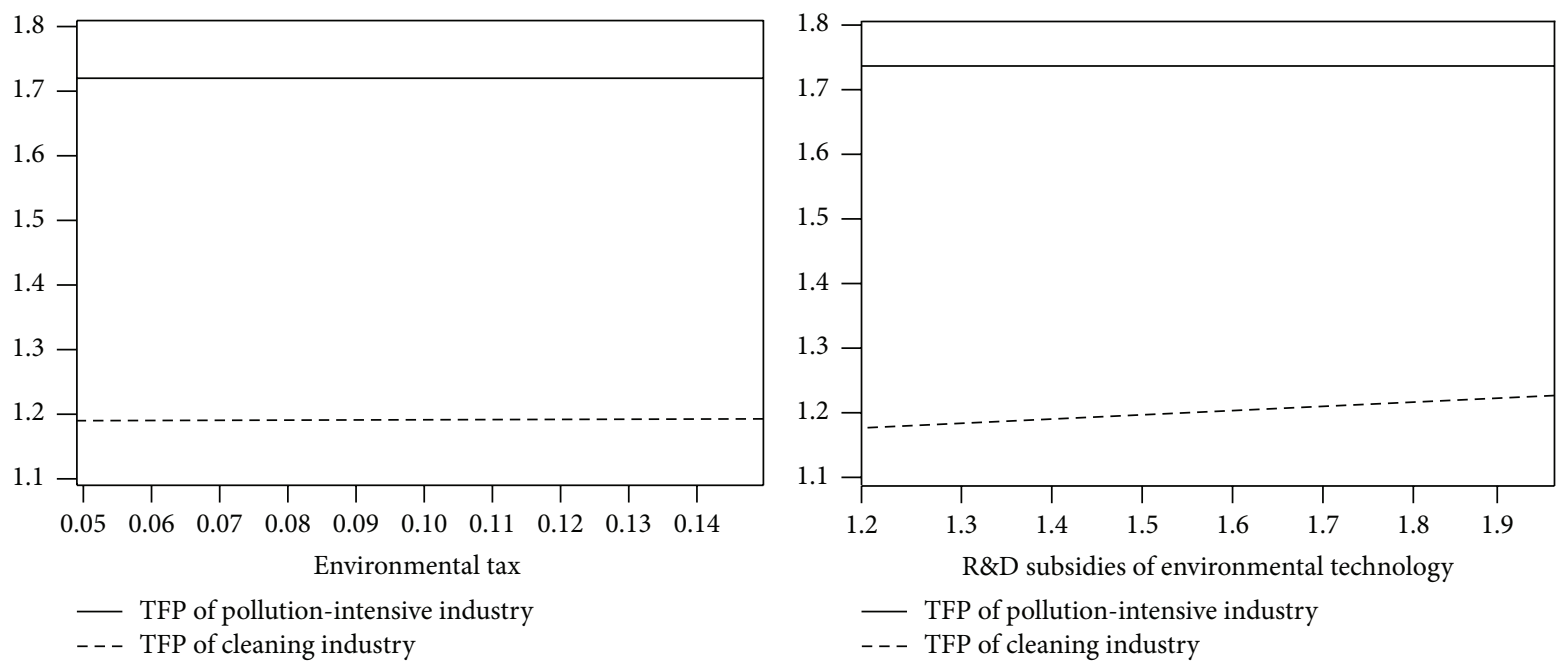

FIGURE 5: The existence analysis of technology spillover effects of market incentives environmental regulation.

decrease the tax burden of environmental tax. Meanwhile, when the environmental regulation intensity is enhanced, the cleansing industries will accelerate the $\mathrm{R} \& \mathrm{D}$ and innovation of technology, enhance the productivity, increase the output, and upgrade the industrial structural transformation for obtaining the competitive edge.

\subsection{The Impact of Market Incentives Environmental Regula- tion on the Industrial Transformation}

(1) Incentive Effects of Technological Innovation. Figure 4 is a comparison of the existence situation related to technological innovation incentive effects of the market incentives environmental regulation in different types of the industry. As shown in Figure 4, the enhancement of the environmental tax and subsidies of environmental technology R\&D do not affect the level of environmental technology as for pollution-intensive industries but promote the cleaning industries to enhance their level of the environmental technology. It means that technological innovation incentive effects of the market incentives environmental regulation do not exist in terms of pollution-intensive industries, while they exist in the cleansing industries. In addition, technological innovation incentive effects of subsidies of environmental technology R\&D should be higher than that of the environmental tax.

(2) Technology Spillover Effect. Figure 5 is a comparison of the existence situation related to technology spillover effects of market incentives environmental regulation in different types of the industry. As shown in Figure 5, the enhancement of the environmental tax and subsidies of environmental technology R\&D do not affect the total factor productivity as for pollution-intensive industries but lead to the increase of the total factor productivity in cleaning industries. It means 

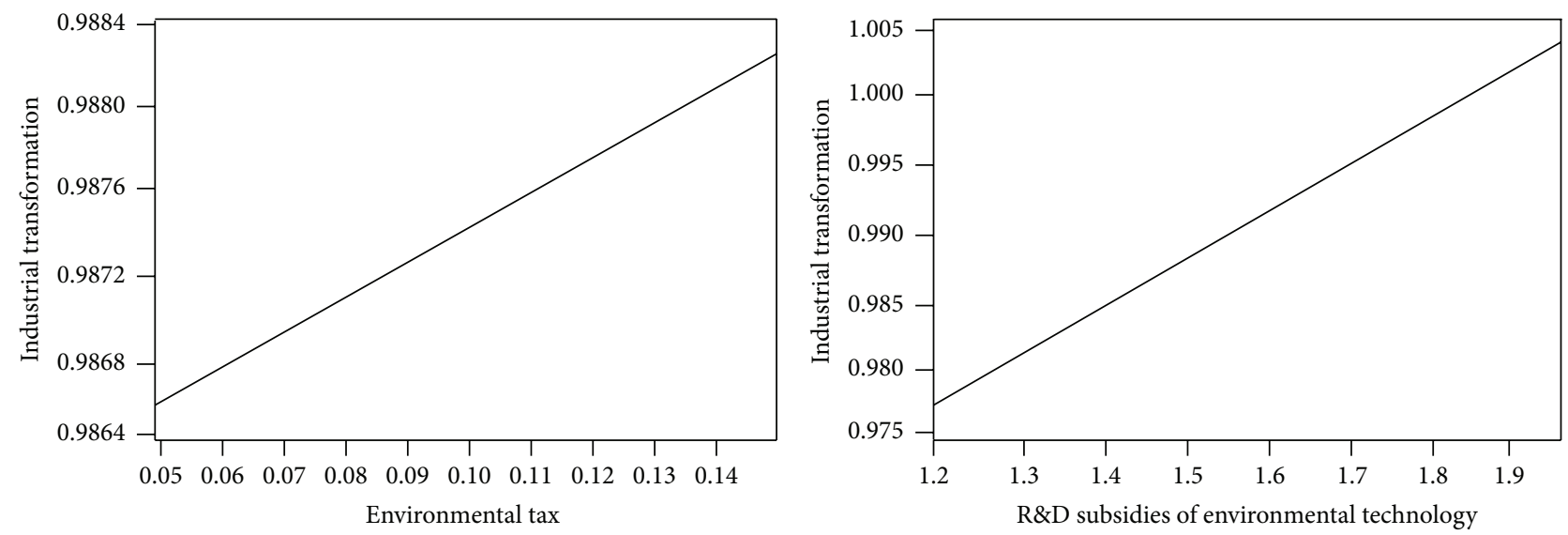

FIGURE 6: The impact of market incentives environmental regulation on the industrial transformation.

that technology spillover effects of the market incentives environmental regulation do not exist in terms of pollutionintensive industries, while they exist in the cleansing industries. In addition, technology spillover effects of subsidies of environmental technology R\&D should be higher than that of the environmental tax.

(3) The Impact of Market Incentives Environmental Regulation on the Industrial Transformation. Figure 6 is the impact of the market incentives environmental regulation on the industrial transformation. As shown in Figure 6, the rise of environmental tax will increase the environmental cost of enterprises. Since the environmental technology of contaminative enterprises is relatively fixed without any other responses except reducing the yield, the pollution-intensive industries still carry out the original mode of production but the equilibrium will be moved down along the original production function. However, the cleaning industries have subjective initiative to deal with environmental tax. Reduction of yield cannot bring the marketing competitive edge for cleaning industries under the condition of environmental tax. Thus, the cleansing industries need to increase the research input of environmental technology to decrease the tax burden of environmental tax. Nevertheless, the motivation of environmental technology innovation is dependent on the relationship between the cost of environmental tax and the cost of environmental technology innovation. In the long run, the cost of environmental tax cleansing industries that the cleansing industries required to pay is inevitably higher than the cost of environmental technology innovation. The technology innovation of cleansing industries will bring the quality improvement of cleaning products and upgrading of the industry. Overall, the real GDP is decreased; the cleansing industries have been developing gradually whereas the pollution-intensive industries have been shrinking. The transformation of industrial structure has been accelerated.

The subsidies of environmental technology R\&D rise and the cost of environmental technology R\&D for cleansing industries reduced so that cleansing industries aspire to increase the input of environmental technology $R \& D$ to promote its improvement. The environmental technology spillover effects of cleansing industries can improve the enterprises' productivity and extend the yield scale since the human resources are trained and the level of management is developed. The increase of capital accumulation portion of all the output in terms of cleansing industries causes the increase of the real GDP. Correspondingly, the part of capital accumulation for pollution-intensive industries will be increased too due to the wealth effect that leads to the output increase. However, the growth of cleansing products output brought by the improvement of environmental technology of cleansing industries exceeds that of pollution-intensive industries, so the industrial structure transformation is upgraded.

Generally speaking, both incentive effects of technological innovation and technology spillover effect exist in the cleansing industries, while both of them do not exist in the pollution-intensive industries. Meanwhile, the environmental regulation policies assist in improving the transformation of industrial structure. There are two influent channels. First, the enhancement of environmental regulation intensity results in the cost increase of pollution emission as for pollution-intensive industries. In the short term, pollutionintensive industries may increase factor input to make up for the loss of pollution emission, but, in the long term, these industries can only maximize the operating profit by reducing the production scale. Second, under the enhancement of environmental regulation intensity, the cleansing industries will improve its level of environmental technology. Technology spillover effects will extend the production scale for the cleansing industries which promote the transformation of industrial structure.

\section{Conclusion}

In this paper, the entire industries are divided into two parts, cleaning industries and pollution-intensive industries. We constructed a mathematical model and conducted numerical simulation; the results indicated that the impact that environmental regulation has on industrial transformation presents comparison of distortion effect of resource allocation and technology effect. Environmental regulation will 
promote industrial transformation when technology effect of environmental regulation is stronger than the distortion effect of resources allocation. Particularly, command-control environmental regulation has a significant incentive effect and spillover effect of technological innovation on cleaning industries, but these effects do not exist in pollution-intensive industries. Command-control environmental regulation promotes industrial transformation. The results of simulation to market incentives environmental regulation are similar to command-control environmental regulation.

According to the conclusion, we suggest that the government should improve the mechanism of investment and financing gradually, widen the ways of financing, accelerate the process of financial reform, and attract private capital into cleaning industries to support the development of cleaning industries to produce technology spillover effect. The government should set up the appropriate environment access standards to guide the environment control and realize the pollution source management for pollution-intensive industry. The government should combine market incentives environmental regulation and command-control environmental regulation effectively to guide cleaning industries to environment governance and improve the effectiveness of environmental regulation.

\section{Competing Interests}

The authors declare that they have no competing interests.

\section{References}

[1] M. E. Porter, "America’s green strategy," Scientific American, vol. 264, no. 4, p. 168, 1991.

[2] M. E. Porter and C. Van Der Linde, "Toward a new conception of the environment-competitiveness relationship," Journal of Economic Perspectives, vol. 9, no. 4, pp. 97-118, 1995.

[3] A. B. Jaffe and K. Palmer, "Environmental regulation and innovation: a panel data study," Review of Economics and Statistics, vol. 79, no. 4, pp. 610-619, 1997.

[4] P. Lanoie, J. Laurent-Lucchetti, N. Johnstone, and S. Ambec, "Environmental policy, innovation and performance: new insights on the porter hypothesis," Journal of Economics and Management Strategy, vol. 20, no. 3, pp. 803-842, 2011.

[5] S. Ambec, M. A. Cohen, S. Elgie, and P. Lanoie, "The Porter Hypothesis at 20: can environmental regulation enhance innovation and competitiveness?" Review of Environmental Economics and Policy, vol. 7, no. 1, pp. 2-22, 2013.

[6] K. Blind, "The influence of regulations on innovation: a quantitative assessment for OECD countries," Research Policy, vol. 41, no. 2, pp. 391-400, 2012.

[7] Y. J. Yuan and R. H. Xie, "Research on the effect of environmental regulation to industrial restructuring empirical test based on provincial panel data of China," China Industrial Economics, no. 8, pp. 57-69, 2014.

[8] Q. Li, "Environmental regulation and industrial structure adjustment: the theoretical analysis and empirical study based on Baumol model," Economics Review, no. 5, pp. 100-107, 2013.

[9] T. Li, "Environmental regulation, service industry development and industrial restructuring," Economic Management, no. 8, pp. 1-10, 2013.
[10] X. J. Bai and Y. Song, "Environment regulation, technology innovation and efficiency improvement of Chinese thermal power industry," China Industrial Economics, no. 8, pp. 68-77, 2009.

[11] C. Zhang, Y. Lu, L. Guo, and T. S. Yu, "The intensity of environmental regulation and technological progress of production," Economic Research Journal, no. 2, pp. 113-124, 2011.

[12] L. Li and F. Tao, "Selection of optimal environmental regulation intensity for Chinese manufacturing industry-based on the green TFP perspective," China Industrial Economics, no. 5, pp. 70-82, 2012.

[13] N. Shen, "Environmental efficiency, industrial heterogeneity and intensity of optimal regulation-nonlinear test based on industrial panel-data," China Industrial Economics, no. 3, pp. 56-68, 2012.

[14] M. Y. Xu and H. P. Zuo, "Study on the relationship between environmental regulation and industrial competitiveness under agglomeration effect: porter Hypothesis re-examination," China Industrial Economics, no. 3, pp. 72-84, 2013.

[15] P. Y. Nie and L. Huang, "An empirical study of environmental regulation's different impact on industrial total factor energy productivity," Industrial Economics Research, no. 4, pp. 50-58, 2013.

[16] Z. Q. Dong, X. Cai, and L. H. Wang, "The direction of technical change, urban land size and environment quality," Economic Research Journal, no. 10, pp. 111-124, 2014.

[17] D. Acemoglu, P. Aghion, L. Bursztyn, and D. Hemous, "The environment and directed technical change," American Economic Review, vol. 102, no. 1, pp. 131-166, 2012.

[18] M. X. Huang and S. F. Lin, "Pollution damage, environmental management and sustainable economic growth-based on the analysis of five-department endogenous growth model," Economics Research, no. 12, pp. 30-41, 2013. 


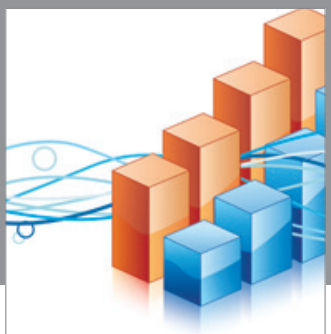

Advances in

Operations Research

vatem alat4

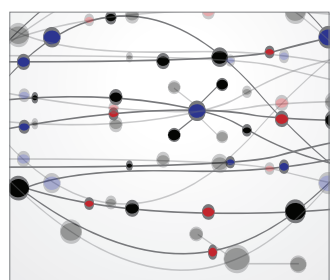

\section{The Scientific} World Journal
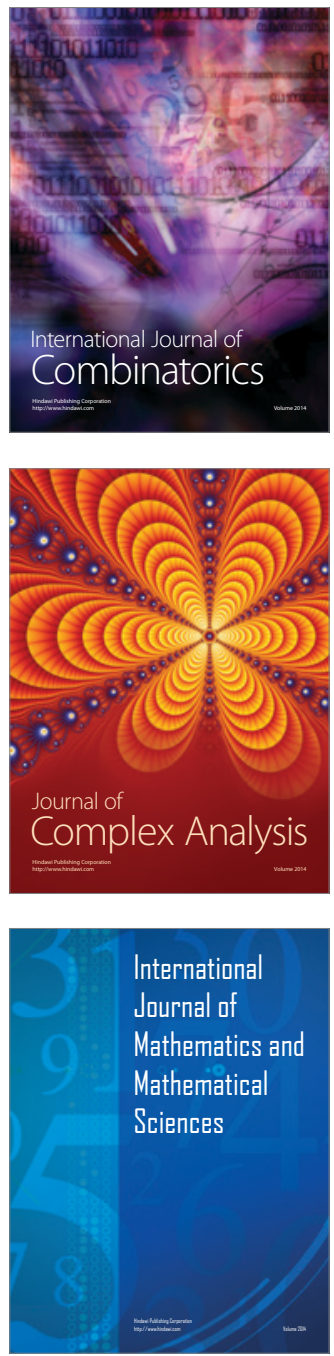
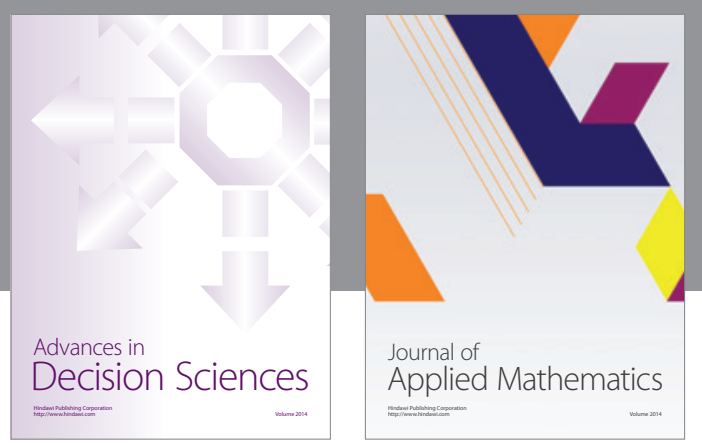

Algebra

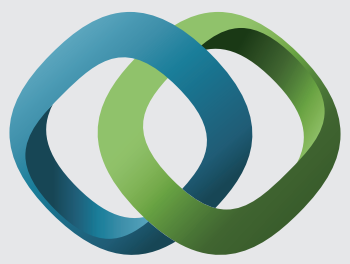

\section{Hindawi}

Submit your manuscripts at

http://www.hindawi.com
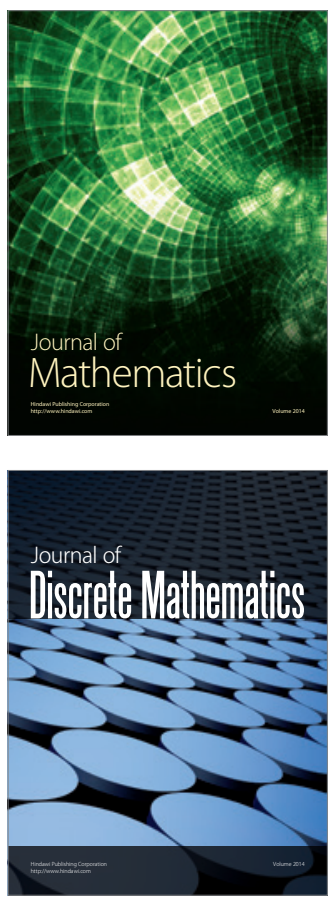

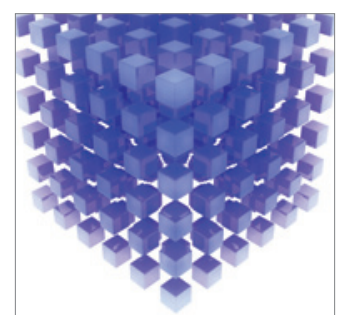

Mathematical Problems in Engineering
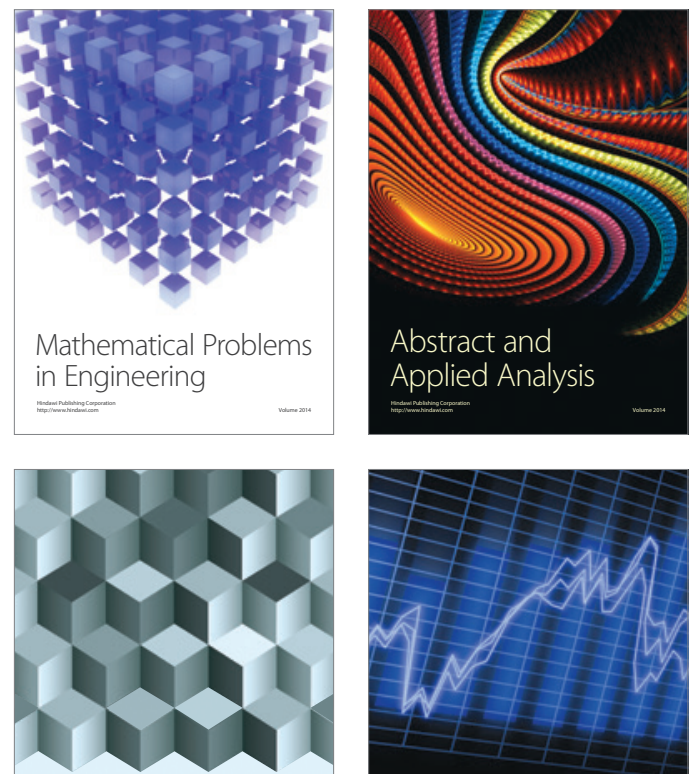

Journal of

Function Spaces

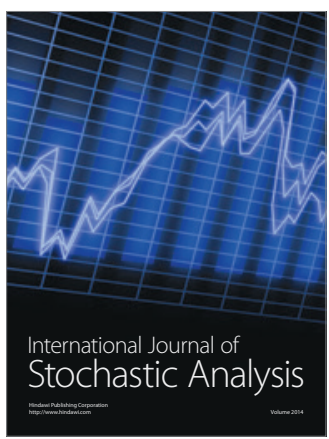

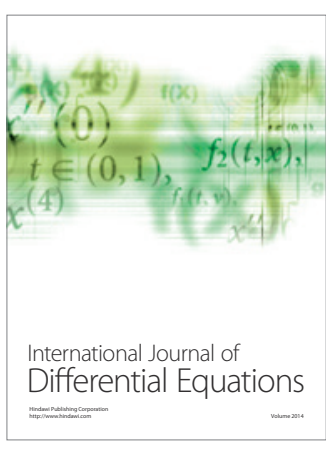
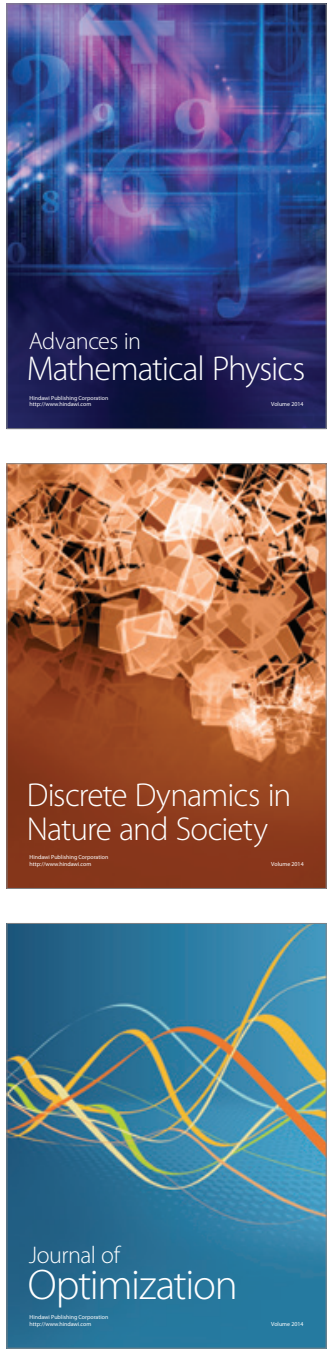